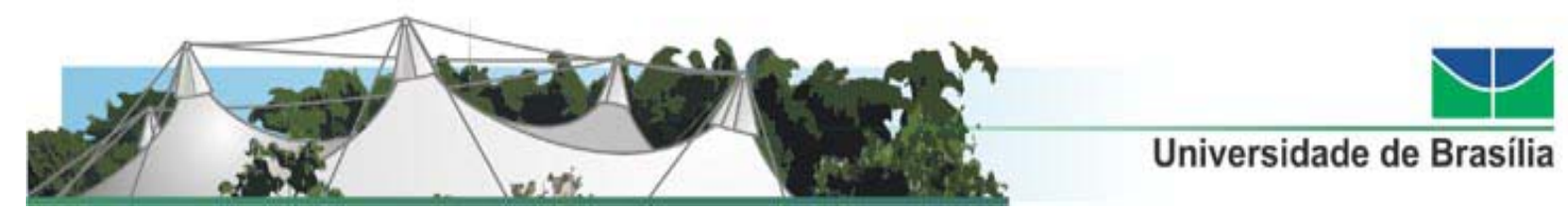

\author{
UNB - UNIVERSIDADE DE BRASÍLIA \\ LICENCIATURA EM CIÊNCIAS BIOLÓGICAS \\ IVONETE CONCEIÇÃO DE OLIVEIRA NOLETO
}

EDUCAÇÃO AMBIENTAL NO CONTEXTO ESCOLA-SOCIEDADE

Brasília - DF 


\section{IVONETE CONCEIÇÃO DE OLIVEIRA NOLETO}

\section{EDUCAÇÃO AMBIENTAL - NO CONTEXTO ESCOLA-SOCIEDADE}

Trabalho de Conclusão de Curso apresentado à Universidade de Brasília - UNB, como exigência parcial para obtenção do título de Licenciado em

Ciências Biológicas sob a orientação: Prof. Lívio Dantas Carneiro.

Brasília - DF 


\section{IVONETE CONCEIÇÃO DE OLIVEIRA NOLETO}

\section{EDUCAÇÃO AMBIENTAL - NO CONTEXTO ESCOLA-SOCIEDADE}

Trabalho de Conclusão de Curso apresentado à Universidade de Brasília - UNB, como exigência parcial para obtenção do título de Licenciado em Ciências Biológicas sob a orientação: Prof. Lívio Dantas Carneiro.

Aprovado em

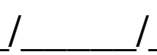

Banca Examinadora:

Prof. Orientador

Prof. Examinador

Prof. Examinador

Brasília-DF 2010 
Dedico este trabalho com muito carinho a minha família que me incentivou a lutar pelos meus ideais e especialmente a Deus que me conduziu para o término de meu curso. 


\section{AGRADECIMENTOS}

Agradeço a Deus, por ter me concedido, através de sua bondade infinita, o potencial de concretizar mais uma conquista em minha vida e ao meu marido e filhos que me apoiaram durante mais essa jornada da minha vida e aos professores que nos deram suporte para prosseguirmos sempre em busca do conhecimento. 


\section{RESUMO}

Este trabalho traz algumas reflexões sobre a Educação Ambiental no contexto escola-sociedade que tem como principal objetivo trabalhar a conscientização da sociedade em relação a preservação e conservação do meio ambiente. A questão ambiental está cada vez mais presente no cotidiano da população das nossas cidades, seja nas escolas, seja nos meios de comunicação, principalmente no que se refere ao desafio de preservar a qualidade de vida, uma vez que se observa que é cada vez mais difícil manter a qualidade de vida nas cidades ou até mesmo no campo. Sendo assim, é preciso fortalecer a importância de garantir padrões ambientais adequados e estimular uma crescente consciência ambiental, centrada no exercício da cidadania e na reformulação de valores éticos e morais, individuais e coletivos, numa perspectiva voltada para o desenvolvimento sustentável. Ainda que as autoridades governamentais tardem em promover projetos que visem a preservação do meio ambiente, é necessário que a escola continue sua luta em prol da "salvação" do planeta.

Palavras-chave: Educação. Conscientização. Preservação. Conservação. 


\section{LISTA DE SIGLAS}

EA Educação Ambiental

EUA Estados Unidos da América

ONU Organização das Nações Unidas

PCNs Parâmetros Curriculares Nacionais

PNUMA Programa das Nações Unidas para o Meio Ambiente

UNESCO Organização para a Educação, a Ciência e a Cultura das Nações Unidas 
ÍNDICE

Introdução 9

1- Histórico da educação ambiental no Brasil 11

2- Conceito de educação ambiental 12

3- A educação ambiental no contexto escolar 13

3.1 A educação ambiental e a interdisciplinaridade 13

4- Problemas ambientais 17

5- Projetos ambientais na escola 20

5.1- A escola em prol do meio ambiente 20

5.2- Escola e comunidade: União e colaboração 21

6- A educação ambiental e o desenvolvimento sustentável 22

7- Conclusão 23

8- Referências bibliográficas 24 


\section{INTRODUÇÃO}

A Educação Ambiental (EA) tornou-se essencial nas escolas e na sociedade, pois é através da mesma que há a perspectiva de mudanças de atitudes, valores e práticas conscientes dos indivíduos em relação a conservação e preservação do meio ambiente e consequentemente em defesa da vida.

É emergencial o momento em que vive a humanidade em relação à degradação do meio ambiente, daí a importância de se desenvolver boas metodologias para promover uma educação ambiental de qualidade. Essa talvez seja o principal desafio da Educação Ambiental: fazer com que os indivíduos e a comunidade tomem consciência do seu meio ambiente e adquiram conhecimentos, habilidades, experiências, valores e a determinação que os tornam capazes de agir, individual ou coletivamente, na busca de soluções para os problemas ambientais, presentes e futuros.

Para que haja mudanças comportamentais na sociedade é preciso que se desenvolva um programa de educação ambiental, que seja efetivo, que promova, simultaneamente, o desenvolvimento de conhecimento, de atitudes e de habilidades necessárias à preservação e melhoria da qualidade ambiental e, consequentemente, da qualidade de vida da sociedade como um todo.

Segundo os Parâmetros Curriculares Nacionais (2000, p.19) uma das questões que levaram a inserir o meio ambiente como tema transversal foi à contribuição, que, em termos de educação, essa perspectiva pode contribuir para "evidenciar a necessidade de um trabalho vinculado aos princípios da dignidade do ser humano, da participação, da co-responsabilidade e da eqüidade".

O foco principal deste trabalho não é abordar com maior ênfase, a interdisciplinaridade, mas chamar atenção para a transversalidade da educação ambiental a qual se refere os Parâmetros Curriculares Nacionais como uma abordagem da EA nas diferentes ciências.

A questão ambiental está cada vez mais sendo inserida na prática pedagógica de inúmeros professores, de diversas áreas do conhecimento. A 
abordagem nos PCNs sobre as questões ambientais e seu caráter transversal direciona professores a refletir sobre a questão e procurar transmitir essas questões aos educandos de forma que busquem juntos soluções para trabalhar em prol do meio ambiente.

Trabalhar uma possível mudança de comportamento das pessoas é de suma importância principalmente no que diz respeito ao consumismo em exagero, colocando em questão a transformação desse consumismo em um consumo racional onde se leva em consideração as vantagens e desvantagens no âmbito de um desenvolvimento social sustentável, econômico e ambiental.

O principal objetivo da EA é conscientizar as pessoas sobre a gravidade dos problemas ambientais e estimulá-las a tentar buscar soluções para estes problemas. Não é um processo fácil e nem rápido, já que nem todas a pessoas têm consciência de que elas mesmas podem estar prejudicando o ambiente e, muitas vezes, não vêem motivos para se preocupar. Mas com um pouco de boa vontade, tanto dos educadores como da população, a educação ambiental pode trazer bons resultados. 


\section{HISTÓRICO DA EDUCAÇÃO AMBIENTAL NO BRASIL}

Alguns incidentes envolvendo usinas nucleares que causaram contaminações tóxicas de grandes proporções, como nos casos de Three-Mile Island nos EUA em 1979, em Bhopal na Índia em 1984 e Chernobyl, na época, União Soviética no ano de 1986, e mais recentemente no Japão a usina nuclear de Fukushima (março de 2011) estimularam o debate público e científico sobre a questão dos riscos nas sociedades contemporâneas.

Segundo Quintino (2006), em 1972, a ONU patrocinou a Conferência de Estocolmo, em que, pela primeira vez, chegou-se a ideia de que a Educação Ambiental é o instrumento para a promoção das mudanças.

Em 1977, reuniu-se a Primeira Conferência Intergovernamental sobre Educação Ambiental, promovida pela UNESCO e pela PNUMA - Programa das Nações Unidas para o Meio Ambiente, na qual definiram-se objetivos e princípios norteadores para a Educação Ambiental em todo o mundo.

No ano de 1988, o Brasil participou de um Seminário Latino-Americano de Educação Ambiental onde foram formuladas recomendações específicas para o continente.

Todo esse trabalho foi baseado na Constituição Federal de 1988 que expõe: Art.225 - todos têm direito ao meio ambiente ecológico/equilibrado, bem de uso comum do povo e essencial à sadia qualidade de vida, impondo-se ao Poder Público e à coletividade o dever de defendê-lo e preservá-lo para a presente e futuras gerações.

$\S 1^{\circ}$ - Para assegurar a efetividade desse direito, incumbe ao Poder Público: VI promover a educação ambiental em todos os níveis de ensino e a conscientização pública para a preservação do meio ambiente. A partir de tal dispositivo cada estado estabeleceu sua constituição estadual. (PETERS, \& PIRES, 2000, p. 26 ). 


\section{CONCEITO DE EDUCAÇÃO AMBIENTAL}

A Educação Ambiental busca despertar a preocupação individual e coletiva para a questão ambiental, sendo o canal de acesso à informação em linguagem adequada, contribuindo para o desenvolvimento de uma consciência crítica e estimulando o enfrentamento das questões ambientais e sociais.

Como uma perspectiva mais abrangente, a EA não restringe seu olhar à proteção e uso sustentável de recursos naturais, mas incorpora fortemente a proposta de construção de sociedades sustentáveis.

A falta de conhecimento sobre o que é EA pode ser a razão de interpretações errôneas. Por exemplo, frequência de aulas ao ar livre, educação para a conservação e estudo da natureza são todos considerados como EA.

A Educação Ambiental aparece como um instrumento que busca a reeducação do cidadão, por conter, em seus princípios, elementos que possibilitem a reflexão das relações socioeconômicas da sociedade, apontando para novas formas de convivência social; contudo, raras são as preocupações a respeito das bases conceituais e epistemológicas sobre as quais ela deverá se desenvolver (GRUN, 2000).

\footnotetext{
"A EA fomenta sensibilidades afetivas e capacidades cognitivas para uma leitura do mundo do ponto de vista ambiental. Dessa forma, estabelece-se como mediação para múltiplas compreensões da experiência do indivíduo e dos coletivos sociais em suas relações com o ambiente. Esse processo de aprendizagem, por via dessa perspectiva de leitura, dá-se particularmente pela ação do educador como intérprete dos nexos entre sociedade e ambiente e da EA como mediadora na construção social de novas sensibilidades e posturas éticas diante do mundo." (Carvalho, Isabel C. M. Educação Ambiental: A Formação do Sujeito Ecológico)
} 


\title{
3 A EDUCAÇÃO AMBIENTAL NO CONTEXTO ESCOLAR
}

A escola é o lugar onde o aluno continuará seu processo de socialização. Tudo o que nela se aprende e se pratica representa um exemplo do que a sociedade espera e aprova. Comportamentos ambientalmente corretos devem ser aprendidos na prática, no cotidiano da vida escolar, contribuindo para a formação de cidadãos responsáveis.

\begin{abstract}
Entende-se por educação ambiental os processos por meio dos quais o indivíduo e a coletividade constroem valores sociais, conhecimentos, habilidades, atitudes e competências voltadas para a conservação do meio ambiente, bem de uso comum do povo, essencial à sadia qualidade de vida e sua sustentabilidade (LEI 9.795, 1999, art. $\left.1^{\circ}\right)$.
\end{abstract}

Levando-se em consideração a importância da educação ambiental e a visão integrada do mundo, no tempo e no espaço, a escola deverá oferecer meios efetivos para que cada aluno compreenda os fenômenos naturais, as ações humanas e sua consequência para consigo, para sua própria espécie, para os outros seres vivos e o ambiente.

É de suma importância que cada indivíduo adote posturas pessoais e comportamentos sociais diferenciados e construtivos, como forma de colaborar para a construção de um ambiente saudável, ou seja um planeta sustentável.

A lei 9.795/99, em seu art. 10, § 10 diz que "A educação ambiental não deve ser implantada como disciplina específica no currículo de ensino". A maneira como o currículo é oferecido na maioria das escolas não permite um arranjo flexível para que os professores possam incluir a dimensão ambiental em suas aulas.

Para Moreira "nas escolas não se aprendem apenas conteúdos sobre o mundo natural e social; adquirem-se também consciência, disposições e sensibilidades que comandam relações e comportamentos sociais do sujeito e estrutura sua personalidade" (1995: 50).

A ação direta do professor na sala de aula é uma das formas de levar a Educação Ambiental à comunidade, pois um dos elementos fundamentais no processo de conscientização da sociedade dos problemas ambientais é o educador. Tendo este o poder de promover ou estimular mudanças de hábitos e atitudes em seus alunos afim de que venham adquirir respeito à natureza, contribuindo assim para que se tornem cidadãos conscientes e comprometidos com o futuro do planeta.

\subsection{A EDUCAÇÃO AMBIENTAL E A INTERDISCIPLINARIDADE.}


A interdisciplinaridade proposta nos PCN assume como elemento ou eixo de integração a prática docente comum voltada para o desenvolvimento de competências e habilidades comuns nos alunos. Essa proposta é interessante, pois ela promove a mobilização da comunidade escolar em torno de objetivos educacionais mais amplos, que estão acima de quaisquer conteúdos disciplinares.

Além da inserção da Educação Ambiental na proposta pedagógica da escola é fundamental que os educadores estejam preparados para incorporar o trabalho de Educação Ambiental à sua práxis, tendo em vista que as questões ambientais fazem parte da vida de todos e devem ser articuladas as diversas áreas do conhecimento.

Com os conteúdos relativos à EA permeando todas as disciplinas do currículo e contextualizados com a realidade da comunidade, a escola ajudará o aluno a perceber a correlação dos fatos e a ter uma visão holística, ou seja, integral do mundo em que vive. Para isso a Educação Ambiental deve ser abordada de forma sistemática e transversal, em todos os níveis de ensino, assegurando a presença da dimensão ambiental de forma interdisciplinar nos currículos das diversas disciplinas e das atividades escolares.

A Educação Ambiental foi definida como uma dimensão dada ao conteúdo e à prática da educação orientada para a solução dos problemas concretos do meio ambiente, através de enfoques interdisciplinares e de uma participação ativa e responsável de cada indivíduo e da coletividade. I Conferência Intergovernamental sobre educação Ambiental - Tbilisi, Geórgia.

Podemos citar por exemplo, a Declaração de Tbilisi, baseada na Carta de Belgrado, que estabeleceu grandes objetivos para a Educação Ambiental:

1) promover clara consciência da interdependência econômica, social, política e ecológica em áreas urbanas e rurais, e uma preocupação por elas;

2) dar a cada pessoa as oportunidades para adquirir o conhecimento, valores, atitudes, compromisso e habilidades necessárias para proteger e melhorar o meio ambiente;

3) criar novos padrões de comportamento nos indivíduos, grupos e na sociedade em geral para com o meio ambiente. 
Conforme o Art. 10 da Política Nacional de Educação Ambiental, a Educação Ambiental será desenvolvida como uma prática educativa integrada, contínua e permanente em todos os níveis e modalidades do ensino formal. É uma vertente da educação voltada para a conscientização ambiental, proporcionando um processo de alfabetização ecológica. A Educação Ambiental pode ser abordada de diferentes formas na sala de aula. O professor deve utilizar metodologias criativas para obter a atenção e participação de todos os alunos, promovendo a conscientização ambiental.

Devem ser desenvolvidas atividades práticas, de modo que os alunos conciliem teoria e prática. Um bom exemplo são as aulas realizadas em zoológicos, parques, praças e até no próprio espaço físico da escola, onde as explicações, juntamente com o contato com os recursos naturais, são de extrema importância no processo de conscientização ambiental.

Ao contrário do que propõe o currículo para as instituições educacionais, como mostra no seguinte artigo;

"Art. $1^{\circ}$ - Os estabelecimentos de ensino pré-escolar e de $2^{\circ}$ graus, oficiais e particulares, incluirão estudos e atividades de Educação Ambiental como conteúdos programáticos das disciplinas de seu currículo pleno, cujo campo de conhecimentos se relacione com os de meio ambiente, ecologia, conservação de recursos naturais e correlatos ou afins"

A Educação Ambiental então passou a ser lembrada na semana do meio ambiente o que se tornou um pretexto para que as escolas se lembrem do ato de educar para o meio ambiente.

Cabe aos professores e demais pessoas ligadas ao ensino, possibilitar a aquisição de conhecimentos relativos ao ambiente, tendo em vista a realidade local, do País, como também a mundial. Isto pode ser feito através do acesso às informações e às diferentes experiências sobre problemas ambientais.

T. M. O. Bezerra e A. A. C. Gonçalves (2007) enfatiza que a relação entre educação ambiental e meio ambiente deve ser alvo de esforços por parte de entidades governamentais e não-governamentais que visem ações educativas formais e informais relativas a tais temas. Em outras palavras, os esforços deveriam ser direcionados no sentido de que seja compreendido que a educação ambiental é, de fato, uma subárea para estudos relacionados ao meio ambiente.

Não se pode esquecer a Matemática, a Língua Portuguesa, a Educação Artística dentre outras, pois que essas disciplinas também podem contribuir, de 
maneira significativa, para o aprofundamento dos temas ligados à Educação Ambiental. 


\section{PROBLEMAS AMBIENTAIS}

Atualmente a sociedade global passa por uma mudança no que se dizem respeito à análise dos problemas ambientais, cada vez mais frequentes, os quais pela sua própria natureza tornam-se mais difíceis de serem previstos e assimilados como parte da realidade global. É claro que nem todo tipo de catástrofe esteja relacionada diretamente às ações antropológicas, mas muitas tragédias poderiam ser evitadas se as pessoas seguissem algumas regras básicas de segurança, como por exemplo, evitar construir suas casas nas encostas dos morros.

É possível afirmar que a inconsciência e a indiferença do ser humano ante o caos ambiental é um dos maiores problemas se não o maior deles enfrentado por nosso Planeta. Isto se deve, em grande parte, não só pela ignorância de muitas pessoas, mas também pela ausência de políticas públicas educacionais adequadas, capazes de provocar o nascimento de uma nova mentalidade a cerca da relação meio ambiente e humanidade. BRANDÃO (2007) reflete sobre a falta de respeito e a perda de valores do homem para com a natureza;

A ameaça a Natureza, os seus ambientes e a Vida, não é apenas a ganância
com que a civilização converte tudo e todos em mercadorias, e se apossa de
tudo o que pode converter em lucro, em nome de um capital sem rosto e
nome, disfarçado, de progresso ou desenvolvimento, mas o fato de todos
estarmos perdendo aos poucos e de maneira universal e crescente, alguns
sentidos essenciais, sentimentos ancestrais e significados a respeito do valor
original de nós mesmos, seres humanos e a respeito do valor Vida
(BRANDÃO, 2007).

Pode-se observar que os problemas ecológicos acontecem com maior intensidade nas metrópoles que nas cidades pequenas ou na zona rural. Além da poluição atmosférica, as metrópoles apresentam outros problemas graves: Acúmulo de lixo e de esgotos. Boa parte dos detritos poderia ser recuperada para a produção de gás (biogás) ou adubos, mas isso dificilmente acontece.

Nesse contexto a escola entra com o papel de trabalhar esses problemas com os alunos sob a forma de debates e palestras mostrando as consequências advindas desses problemas, sempre buscando juntamente com a comunidade escolar e a vizinhança, meios para amenizá-los. A escola pode e deve lançar projetos juntamente com os alunos e a comunidade local, com a finalidade de aproveitamento do lixo através da reciclagem o que além de gerar renda ajuda na preservação do meio ambiente. 
Para Maranhão (2005), é dever de todo cidadão combater os problemas ambientais criados pelo próprio homem ao longo dos séculos:

\begin{abstract}
As consequências de sua destruição atingem todas as nações e é preciso que todas assumam o compromisso de combater o problema em seus territórios. Entretanto, após séculos de agressão, uso e abuso dos recursos naturais, não vem sendo fácil convencer os indivíduos (e seus governos) de que são apenas partes de um sistema com o qual devem viver em harmonia, sob pena de sofrerem os efeitos que tornarão sua estadia no planeta cada vez mais penosa: entre eles o aquecimento global, gerado pela concentração dos gases de efeito estufa na atmosfera, acompanhado por mudanças violentas nos fenômenos climáticos; a escassez de água; a desertificação que torna os solos estéreis a atividades agrícolas (p. 7).
\end{abstract}

Segundo Bateson (1987), os problemas enfrentados hoje pela natureza, não passa de consequências das ações do homem durante gerações. Com o advento da Revolução Industrial, a natureza sofreu um grande impacto do homem sobre ela. A humanidade então passa a ter uma percepção de que é necessário reverter esse quadro como forma de garantir sua sobrevivência.

Muitos são os problemas enfrentados hoje pela humanidade que podem ser considerados de natureza grave, tais como; crescimento da população mundial; destruição progressiva da camada de ozônio por gases altamente nocivos; destruição da biodiversidade ou a extinção de espécies; aquecimento global; poluição e indisponibilidade de água potável.

Para Oliveira (1973), a produção exagerada de lixo que tem como causa principal o acentuado crescimento demográfico, principalmente nas grandes cidades, o qual é resultado do êxodo rural e da falta de planejamento familiar.

A questão do lixo é das mais preocupantes e diz respeito a cada ser humano. Tratar a problemática da produção e destinação do lixo no processo de educação é um desafio, cuja solução passa pela compreensão do indivíduo como parte atuante no meio em que vive.

A transformação desses resíduos é muito lenta, principalmente em relação aos materiais que não são biodegradáveis como, no caso do plástico, que demora muito tempo para se decompor na natureza. Diante disso, o homem se vê na necessidade de encontrar um destino adequado para tais resíduos.

Uma maneira utilizada e a mais prejudicial de todas para se livrar de todo esse lixo, é a queima destes materiais, o que provoca a liberação de grande quantidade de gases tóxicos e resíduos nocivos ao solo. 
Atualmente a luta pela preservação do meio ambiente, e a própria sobrevivência do homem no planeta, está em maior parte relacionada com a questão do lixo urbano. 


\section{PROJETOS AMBIENTAIS NA ESCOLA}

A educação ambiental, como artifício para formar cidadãos responsáveis e preocupados com o futuro do planeta, vem adquirindo ao longo dos tempos uma relação homem/natureza com o objetivo de desenvolver na sociedade o senso crítico que vise a conscientização desta no sentido de combater a destruição do meio ambiente através de atitudes que garanta melhores condições e qualidade de vida às gerações futuras. Para tanto é necessário que a escola como um todo desenvolva projetos que envolva a sociedade buscando em conjunto as mudanças de atitudes de cada indivíduo.

\subsection{A ESCOLA EM PROL DO MEIO AMBIENTE}

Estimular o aluno a desenvolver habilidades necessárias para participar produtivamente na solução de problemas ambientais atuais e na prevenção de problemas ambientais futuros é dever da escola. Também se deve esclarecer aos alunos que não existe um órgão ou empresa responsável pelos problemas ambientais pois os problemas ambientais são causados pela sociedade, por cada um de nós.

Observar a realidade que nos cerca e agir em prol de melhorias em qualidade de vida, é mais que uma obrigação pessoal é garantir um futuro melhor às gerações vindouras. Para tanto é necessário que haja projetos governamentais e não governamentais que combatam os problemas ambientais.

Ao programar um projeto de educação ambiental, busca-se desenvolver valores e pensamentos que levem o cidadão a refletir sobre suas atitudes que muitas vezes por ele passam despercebidos. Além disso, o projeto facilita aos alunos e à população uma compreensão fundamental dos problemas existentes, da presença humana no ambiente, da sua responsabilidade e do seu papel crítico como cidadãos de um país e de um planeta.

Segundo Vasconcellos (1997), a presença, em todas as práticas educativas, da reflexão sobre as relações dos seres entre si, do ser humano com ele mesmo e do ser humano com seus semelhantes é condição imprescindível para que a Educação Ambiental ocorra. Dentro desse contexto, sobressaem-se as escolas, como espaços privilegiados na implementação de atividades que propiciem essa 
reflexão, pois isso necessita de atividades de sala de aula e atividades de campo, com ações orientadas em projetos e em processos de participação que levem à autoconfiança, à atitudes positivas e ao comprometimento pessoal com a proteção ambiental implementados de modo interdisciplinar (DIAS, 1992).

\subsection{ESCOLA E COMUNIDADE; UNIÃO E COLABORAÇÃO}

O propósito da EA é dotar os indivíduos com: o conhecimento necessário para compreender os problemas ambientais; as oportunidades para desenvolver as habilidades e capacidades necessárias para investigar avaliar as informações disponíveis sobre os problemas.

Segundo FREIRE (1980, p. 26), "a conscientização implica, pois, que ultrapassemos a esfera espontânea de apreensão da realidade, para chegarmos a uma esfera crítica". Assim sendo a conscientização envolve tanto os alunos quanto a sociedade como um todo.

Uma solução bastante razoável é a coleta seletiva do lixo que deve ser trabalho na escola e estendido à comunidade como forma de redução do uso de recursos naturais e os problemas relativos ao destino do lixo.

Em algumas partes do Brasil, a coleta seletiva já acontece. Através dessa coleta, alguns materiais podem ser reaproveitados ou reciclados, neste último caso sendo a forma mais adequada, por razões ecológicas e econômicas (SCARLATO \& PONTIN, 1992, p.58).

Envolver a comunidade em projetos sócio-ambientais é uma das melhores maneiras de unir forças para combater problemas ambientais locais e consequentemente para o planeta. Para tanto, as palestras e seminários são grandes aliados nessa luta. Assim sendo, a escola deve ser protagonista na organização de projetos, palestras e outros recursos juntamente com a colaboração da administração pública.

Para que um projeto de educação ambiental seja eficaz deve-se promover de forma conjunta o desenvolvimento de conhecimentos, de atitudes e de habilidades necessárias que visem a melhoria da qualidade ambiental. Dessa forma a escola juntamente com a sua vizinhança deverá trabalhar a conscientização ecológica de toda população de forma a estender esse pensamento a toda a cidade, a região, o país, o continente e o planeta se possível for. 


\section{A EDUCAÇÃO AMBIENTAL E O DESENVOLVIMENTO SUSTENTÁVEL}

A busca incessante do desenvolvimento econômico gera uma série de alterações irreversíveis ao meio ambiente. Destruição da vegetação natural, a contaminação das águas, chuvas ácidas, a desertificação de grandes regiões desmatadas, os altos índices de desemprego, o crescimento da criminalidade, a falta de acesso à educação e à saúde, a fome, servem para dimensionar o problema, ao tempo em que evidenciam a ação predadora do homem. SANTOS (1997.p.98) trata da conduta comportamental de cada indivíduo de forma ética em relação a natureza.

"o estudo da conduta, ou a própria conduta, comportamental do ser humano em relação à natureza, decorrente da conscientização ambiental e conseqüente compromisso personalíssimo preservacionista, tendo como objetivo a conservação da vida global".

Assim, Oliveira (2004, p. 25) considera que: Neste sentido, surgiram os princípios da vida sustentável: respeitar e cuidar da biosfera, melhorar a qualidade da vida humana, conservar a vitalidade e a diversidade do planeta Terra, minimizar o esgotamento dos recursos não- renováveis, permanecer nos limites da capacidade de suporte do planeta, modificar atitudes e práticas pessoais, permitir que as comunidades cuidem do seu próprio ambiente, gerar uma estrutura nacional para a integração de desenvolvimento e conservação e constituir uma aliança global. (CAPRA, 2005.p. 17). Afirma que:

"O principal desafio deste século - para os cientistas sociais, os cientistas da natureza e todas as pessoas - será a construção de comunidades ecologicamente sustentáveis, organizadas de tal modo que suas tecnologias e instituições sociais suas estruturas materiais e sociais - não prejudiquem a capacidade intrínseca da natureza de sustentar a vida"

Toda a natureza deve ser encarada como um bem comum a humanidade, sendo responsabilidades de cada cidadão cooperar para a preservação da mesma afim de alcançar de forma coletiva a sustentabilidade. 


\section{CONCLUSÃO}

Vivemos a necessidade urgente de se preservar os recursos naturais e, para isso, torna-se essencial a busca de novos modelos de desenvolvimento sustentável, novo comportamento de consumo, mudança de visão dos recursos naturais, dentre tantas outras de fundamental importância para uma vida equilibrada, posturas estas que vão de encontro com a cultura que vigora na nossa sociedade. É necessário educação, sensibilização e mobilização das pessoas para um consumo consciente, já que a discussão vai muito além.

A busca por uma educação autentica, com professores e alunos autônomos que tenham "capacidade de assumir uma presença consciente no mundo" FREIRE (1996), é uma busca constante que transcende ao desenvolvimento de uma consciência ambiental, pois a Educação Ambiental articulada às práticas de ensino no contexto escolar só será possível com o desenvolvimento pleno do ser humano.

Cabe ao poder público, criar mecanismos através de leis mais eficazes para defesa do meio ambiente e a cada cidadão tomar consciência do dever de cuidar da natureza como um bem comum a todos.

Meio ambiente e desenvolvimento devem ser pensados de maneira sustentável para que as pessoas tenham condições de viver de forma digna e com qualidade de vida por meio do desenvolvimento econômico e a conservação dos recursos ambientais, pois nossa Constituição nos garante o direito a um meio ambiente equilibrado e uma vida saudável dentre outras também de fundamental importância.

Eis um grande desafio para a Educação: mudar a mentalidade das pessoas para que haja reflexos no comportamento e consequentemente atitudes ecologicamente corretas. Cada gesto mesmo que seja considerados pequenos hábitos do nosso cotidiano como fechar as torneiras ao escovar os dentes, escolher produtos recicláveis, embalagem biodegradáveis, dentre tantos outros gestos diminutos já é um ótimo começo rumo a "salvação" do planeta. 
Referências Bibliográficas

AB `SABER, Aziz. (Re)conceituando Educação Ambiental. Rio de Janeiro: Museu de Astronomia e Ciências Afins, 2000.

BATESON, G. Natureza e espírito. Lisboa: Dom Quixote, 1987.

BEZERRA T. M. O; GONÇALVES A. A. C. Concepções de meio ambiente e educação ambiental por professores da Escola Agrotécnica Federal de Vitória de Santo Antão-PE. Revista Biotemas. Santo Antão, set. 2007.p.122

BRANDÃO, M. M. Natureza e aventura: A mídia e seus mitos. In: Il CONGRESSO BRASILEIRO DE ATIVIDADES DE AVENTURA, 2007, Governador Valadares Mg. ANAIS... Minas Gerais, 2007

CAPRA, Fritjof. As Conexões Ocultas: Ciência para uma vida sustentável. CIPOLLA, Marcelo Brandão, tradução. São Paulo: Cultrex, 2005

FREIRE, P. Pedagogia da autonomia. São Paulo: Paz e Terra, 1996.

GRÜN, M. (2000). Ética e educação ambiental: a conexão necessária. Campinas: Papirus.

MARANHÃO, Magno de Aguiar. Educação ambiental: a única saída. Maio. 2005.Disponível em: <www.magnomaranhao.pro.br> Acesso em: 11 nov. 2010.p.7

MOREIRA, A . F. Currículos e Programas no Brasil. Campinas: Papirus, 1995.

OLIVEIRA, Walter Engracia de. Resíduos sólidos e limpeza urbana. São Paulo:USP/MEC, 1973.

QUINTINO, Carlos Alberto Alves. Um histórico sobre a educação ambiental no Brasil e no mundo, 2006. Acesso em 16 jan. 2011.Fonte: http://www.webartigos.com/articles/64178/1/Historia-da-Educacao-

Ambiental/pagina1.html\#ixzz1MquelROx

SANTOS, Antonio Silveira R. dos. Biodiversidade: desenvolvimento sustentável. Revista de Direito Ambiental, São Paulo: RT, ano 2, n.7, julho-set 1997, p. 9

SCARLATO, Francisco Capuano; PONTIN, Joel Arnaldo. Do Nicho ao Lixo. Ambiente, Sociedade e Educação. São Paulo: Atual, 1992.p.58

VASCONCELLOS, H. S. R. A pesquisa-ação em projetos de Educação Ambiental. In: PEDRINI, A. G. (org). Educação Ambiental: reflexões e práticas contemporâneas. Petrópolis, Vozes, 1997.

http://www.planalto.gov.br/ccivil_03/Leis/L9795.htm. Acesso em 18 jan. 2011.

http://pga.pgr.mpf.gov.br/pga/educacao/que-e-ea/o-que-e-educacao-ambiental. Acesso em 05 de maio de 2011. 